\title{
Two Special Organelles found in Trypanosoma cruzi*
}

\author{
WANDERLEY DE SOUZA, ISABEL PORTO CARREIRO, \\ KILDARE MIRANDA and NARCISA L. CUNHA E SILVA \\ Laboratório de Ultraestrutura Celular Hertha Meyer, \\ Instituto de Biofísica Carlos Chagas Filho, CCS-Bloco G, \\ Universidade Federal do Rio de Janeiro, Ilha do Fundão - 21949-900 Rio de Janeiro, Brazil \\ Manuscript received on May 18, 2000; accepted for publication on May 22, 2000; \\ contributed by WANDERLEY DE SOUZA**
}

\begin{abstract}
We review here two unique organelles from Trypanosoma cruzi. One of them is the acidocalcisome, cytoplasmic vacuoles containing a very high $\mathrm{Ca}^{2+}$ concentration and a $\mathrm{Ca}^{2+}-\mathrm{H}^{+}$translocating ATPase activity, present in all trypanosomatids. The other organelle is the reservosome, site of accumulation of endocytosed macromolecules, very rich in cysteine proteinase, that is present only in epimastigote forms of trypanosomes belonging to the Schyzotrypanum sub-genus.
\end{abstract}

Key words: acidocalcisome, reservosome, Trypanosoma cruzi.

\section{INTRODUCTION}

The protozoa kingdom comprises a large number of species, including some which are agents of human and veterinary diseases such as malaria, leishmaniasis, Chagas' disease, African trypanosomiasis, amebiasis, giardiasis, toxoplasmosis, coccidiosis, theileriosis, and babesiosis, to mention only those more important. Some of these protozoa, as is the case of Trichomonas, present a simple life cycle. For others, however, as occurs with Apicomplexa (which includes Plasmodium, Toxoplasma, Eimeria, etc), and some trypanosomatids, the life cycle is relatively complex, displaying several developmental stages in the vertebrate host and, in some cases, in invertebrate hosts. These protozoa are also of interest from the cell biology point of view since they present special

\footnotetext{
Dedicated to the memory of Prof. Carlos Chagas Filho *Invited paper

*** Member of the Academia Brasileira de Ciências

Correspondence to: Wanderley de Souza

E-mail: wsouza@biof.ufrj.br
}

cytoplasmic structures and organelles which have been studied in some detail in the last years providing new information of general biological interest. Here we intend to review the available data about two organelles found in Trypanosoma cruzi which has been the subject of investigation in our laboratory in the last years.

\section{THE ACIDOCALCISOME}

Since the beginning of the of the XX century the microscopists have observed the presence of metachromatic granules, designated as volutin granules, in microoganims stained with basic dyes (Meyer 1904). In protozoa this structure was described in 1958 (Ormerod 1958) and has received several designations such as reservoir of metabolic products, pigment bodies, osmiophilic granules, polyphosphate granules or volutin granules (Anderson \& Ellis 1965, Heywood et al. 1974). Some studies showed that some of the vacuoles contain a lin- 
ear polymer of orthophosphate residues linked by high-energy phosphoanhydre bonds, forming the so called polyphosphates, or to contain pyrophosphate (Review in Docampo \& Moreno 1999). Biochemical studies have indicated the presence of phosphate-containing granules in several trypanosomatids, however their subcellular localization was not well established (Janakidevi et al. 1965, Blum 1989). On the other hand, electron microscopic studies have shown the presence of electron-dense structures in the cytoplasm of trypanosomatids suggested to contain polyphosphates, although no chemical evidence for their presence was presented (Vickerman \& Tetley 1977, Williamson \& McLaren 1981). In any way structures designated as electron-dense granules, volutin granules or inclusion vacuoles have been considered for many years as part of the structure of trypanosomatids, but without any special relevance for the cell physiology. The use of X-ray microanalysis, where it is possible to correlate an image seen in the transmission electron microscope with the elemental composition, showed the presence of $\mathrm{Ca}, \mathrm{P}, \mathrm{Mg}, \mathrm{Na}, \mathrm{Zn}$ and $\mathrm{Fe}$ in the cytoplasmic electron-dense granules of trypanosomatids (Vickerman \& Tetley 1977, Carvalho \& De Souza 1977, Williamson \& McLaren 1981, Dvorak et al. 1988, LeFurgey et al. 1990, Miranda et al. 2000). At least three types of dense granules can be found in trypanosomatids. One is homogeneous, is not membrane bounded, does not present electron-lucent areas, and is possibly constituted by lipids, since it is not visualized as dense granules in cells not fixed with osmium tetroxide. A second type corresponds to lipid granules, is membrane bounded and found in Crithidia deanei (Soares \& De Souza, 1988). A third type of granule seems to be related with the iron metabolism, accumulating hemo derivatives. For instance, the large dense granule found in Trypanosoma cyclopis depends on the presence of hemoglobin in the culture medium (Heywood et al. 1974). Peroxidase activity can be detected in these granules (Carvalho et al. 1979). The fourth type of dense granule is observed in all trypanosomatids and will be the subject of the comments below.

A major breakthrough on the study of cytoplasmic vacuoles of trypanosomatids took place in 1994 when Vercesi et al. put together at least two basic information: (a) previous observations made in trypanosomatids showing the existence of an intracellular $\mathrm{Ca}^{2+}$ pool that was released when the cells were treated with nigericin (Philosoph \& Zilberstein 1989, Ruben et al. 1991) and the cytoplasm became acidic (Ruben et al. 1991), and (b) observations carried out in the slime mold Dictiostelium discoideum and in mammal cells showing the existence of acidic organelles showing an ATP-driven $\mathrm{Ca}^{2+}$ $\mathrm{H}^{+}$antiport and containing a vacuolar-type $H^{+}$. ATPase, named as acidosomes (Rooney \& Gross 1992, Nolta et al. 1991, Meldolesi et al. 1990). In addition Vercesi et al. (1994) added the basic information that $\mathrm{Ca}^{2+}$ was released from the intracellular pool, not because of acidification of the cytosol by nigericin, but because this drug released the ions from intracellular acidic vacuoles. Based on the fact that the cytoplasmic vacuoles contained a very high $\mathrm{Ca}^{2+}$ concentration and a $\mathrm{Ca}^{2+}-\mathrm{H}^{+}$translocating ATPase activity, the organelle, first characterized in Trypanosoma brucei, was designated as acidocalcisome (Vercesi et al. 1994).

Following the initial observations carried out in T. brucei, Docampo and co-workers have extended their studies and showed the presence of acidocalcisomes in other trypanosomatids, such as Trypanosoma cruzi (Docampo et al. 1995), Leishmania amazonensis (Lu et al. 1997), Toxoplasma gondii (Moreno \& Zhong 1996) and Plasmodium falciparum (Marchesini et al. 2000).

From the morphological point of view, the structure now designated as acidocalcisome has been observed since the first observations of thin sections of trypanosomatids by electron microscopy. It is a membrane bounded structure with an electrondense content. The amount of dense material varies according to the procedures used to prepare the samples for electron microscopy. In routine procedures 
part of the dense material may be removed, leaving a thin dense ring below the membrane. Electrondense product is seen within acidocalcisomes of cells fixed in the presence of potassium pyroantimonate which precipitates calcium (Lu et al. 1998). The whole material is better preserved in cells fixed using the high-pressure freezing method followed by freeze-substitution where all acidocalcisomes appear as an organelle completely filled with the electron-dense material (Miranda et al. 2000). A similar aspect is also observed in frozen sections (Scott et al. 1997, Miranda et al. 2000). The best way to have a general view of all acidocalcisomes is the observation of a whole cell allowed to dry onto carbon and formvar-coated grids in the transmission electron microscope, especially if it is equipped with an energy filter, so that the electron spectroscopic images can be obtained (Miranda et al. 2000).

The acidocalcisome usually appears as a spherical structure with an average diameter of $200 \pm 90$ $\mathrm{nm}$. It can be observed in all portions of the cell, although are preferentially located at the cell periphery. In epimastigotes, they are especially concentrated in the middle portion of the body, although some are observed in the cell body region associated with the flagellum. In trypomastigotes, they are preferentially localized in the anterior portion. Although usually randomly distributed, in some cells they were seen in an aligned organization, suggesting interactions with cytoskeletal components of the cell. Close contact between the acidocalcisome and nucleus, lipid inclusions, mitochondria and sub-pellicular microtubules has been observed.

The number of acidocalcisomes varies from species to species and even in the various developmental stages of the same species. A morphometrical study recently carried out in $T$. cruzi showed that amastigote forms possessed greater numbers of acidocalcisomes, occupying a larger volume of the cell, as compared with epimastigotes and trypomastigotes (Miranda et al. 2000). Table I summarizes the most important morphometrical data. Refer to
Figures 1 and 2 for a review on the morphological aspects of the $T$. cruzi acidocalcisomes under different TEM specimen preparation conditions, imaging recording and analysis.

The first indication that the acidocalcisome is an acidic organelle came from studies where it was shown that the inclusion vacuoles found in procyclic forms of $T$. bruce $i$ became larger when the cells were cultivated in the presence of chloroquine, an acidotropic drug (Coppens et al. 1993). Later on, it was shown by fluorescence microscopy that round vacuoles of varying size found in T. brucei and T. cruzi were labeled with acridine orange, and that the accumulation of this dye was sensitive to bafilomycin A, nigericin, and $\mathrm{NH}_{4} \mathrm{Cl}$ (Vercesi et al. 1994, Docampo et al. 1995). In the case of epimastigotes of T. cruzi, it is important to have in mind that another acidic organelle, the reservosome, also concentrates acridine orange (Soares et al. 1992). The exact $\mathrm{pH}$ of the acidocalcisome has not been determined yet.

From a biochemical point of view we should consider two basic components of the acidocalcisome: the matrix and the membrane.

The matrix of the acidocalcisome has been mainly analyzed in terms of its elemental composition based mainly on analytical methods associated with electron microscopy. In these experiments, the element content is compared between the inner portion of the organelle and other portions of the cell, such as the cytoplasm. The following elements have been shown to be concentrated into the acidocalcisome: $\mathrm{P}, \mathrm{Mg}, \mathrm{Ca}, \mathrm{Na}$ and $\mathrm{Zn}$, and very little $\mathrm{Cl}, \mathrm{K}$ and S (Dvorak et al. 1988, LeFurgey et al. 1990, Scott et al. 1997, Miranda et al. 2000). The low content of S suggests a low content of proteins. It is important to point out that care should be taken in the interpretation of microanalytical data, especially if fixed cells are used. It is well known that fixation changes the permeability of cell membranes to some ions. Electron energy loss spectroscopy revealed the presence of $\mathrm{P}$ and $\mathrm{O}$, suggesting the presence of carbohydrates (Scott et al. 1997). Recent studies have shown that the phosphorus observed in 


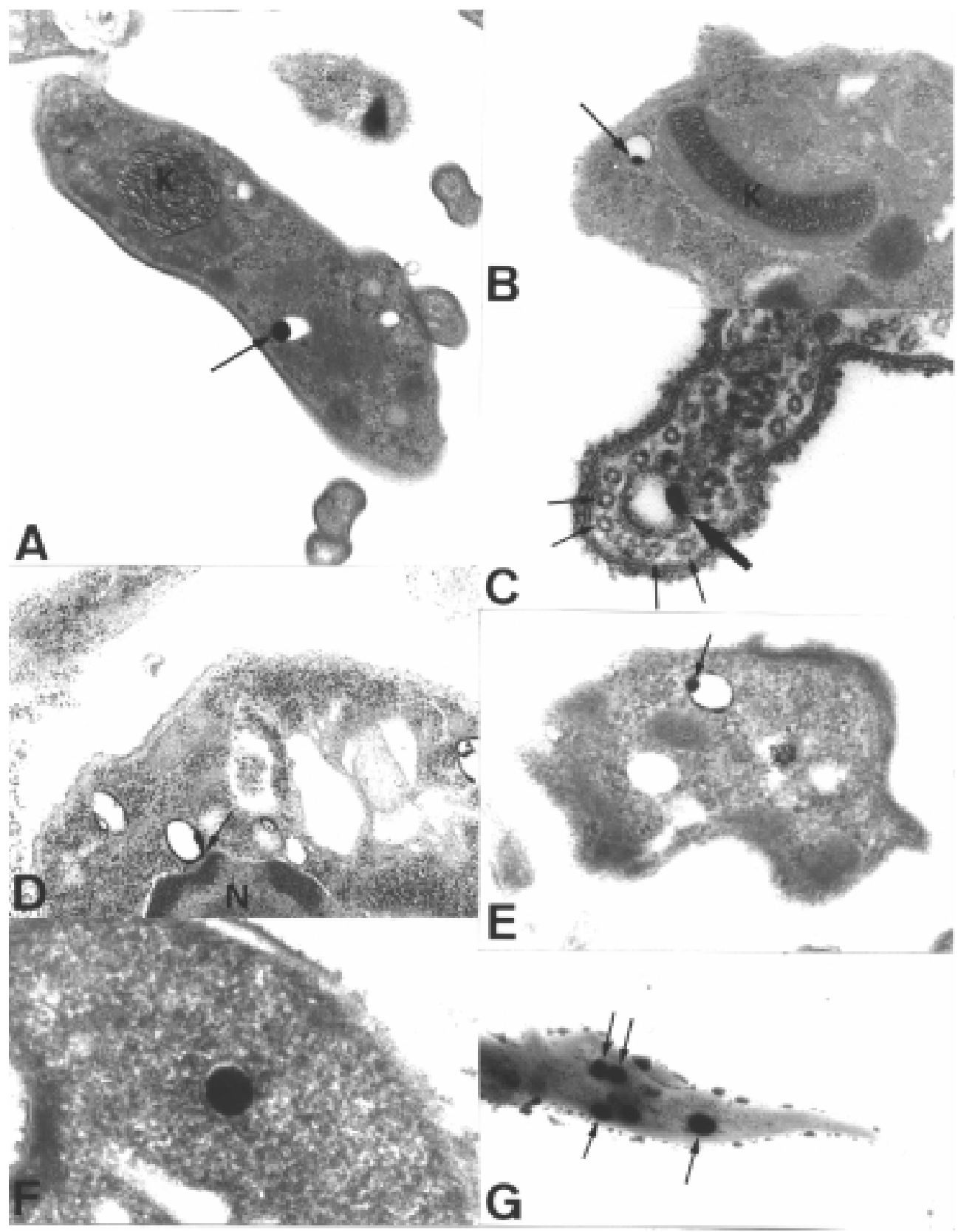

Fig. 1 - Thin sections of $T$. cruzi acidocalcisomes submitted to different protocols for transmission electron microscopy. The organelle can be easily recognized in Epon sections in the trypomastigote (A), epimastigote (B) and amastigote (D) forms as empty vacuoles with the electron-dense inclusion located below the acidocalcisome membrane (arrows). It can be seen in close contact with other parasite organelles such as kinetoplast (B), subpellicular microtubules (C) and nucleus (D). The morphological aspect of the acidocalcisomes remains the same in Unicryl sections (E), whereas in high pressure freezing followed by freeze substitution (F) and cryoultramicrotomy followed by freeze-drying $(\mathrm{G})$ the electrondense content is well preserved. (A) X 23,400 (B) X 27,000 (C) X 94,800 (D) X 38,300 (E) X 28,400 (F) X 82,700 (G) X 16,300. 
TABLE I

Distribution of acidocalcisomes in Trypanosoma cruzi.

\begin{tabular}{c|c|c|c|c}
\hline $\begin{array}{c}\text { Developmental } \\
\text { Stage }\end{array}$ & Source & $\begin{array}{c}\% \text { of Volume } \\
\text { occupied by } \\
\text { acidocalcisomes }\end{array}$ & $\begin{array}{c}\text { No. of } \\
\text { acidocalcisomes }\end{array}$ & $\begin{array}{c}\text { Absolute vol. of } \\
\text { acidocalcisomes } \\
\left(\mu \mathrm{m}^{3} \times 10^{-3}\right)\end{array}$ \\
\hline Amastigote & $\begin{array}{c}\text { Released from } \\
\text { fibroblasts }\end{array}$ & $1.94 \pm 0.18$ & $46 \pm 2$ & $0.96 \pm 0.13$ \\
\hline Amastigote & $\begin{array}{c}\text { Released from } \\
\text { myoblasts }\end{array}$ & $2.32 \pm 0.36$ & N.D. & N.D. \\
\hline Amastigote & $\begin{array}{c}\text { Intracellular } \\
\text { (VERO cells) }\end{array}$ & $2.01 \pm 0.11$ & N.D. & N.D. \\
\hline Trypomastigote & $\begin{array}{c}\text { Released from } \\
\text { fibroblasts }\end{array}$ & $0.51 \pm 0.08$ & $17 \pm 1$ & $0.52 \pm 0.10$ \\
\hline Trypomastigote & $\begin{array}{c}\text { Released from } \\
\text { myoblasts }\end{array}$ & $0.26 \pm 0.06$ & N.D. & N.D. \\
\hline Epimastigote & LIT & $0.86 \pm 0.14$ & $30 \pm 1$ & $2.43 \pm 0.75$ \\
\hline
\end{tabular}

N.D. = Not determined.

acidocalcisomes of $T$. cruzi is present in the forms of PPi and short-chain polyphosphates. In addition, PPi seems to be the most abundant high energy phosphate present in T. cruzi (Urbina et al. 1999) and T. gondii (Rodrigues et al. 2000).

The membrane of the acidocalcisome is $8 \mathrm{~nm}$ thick. The membrane was not yet isolated so that there are few information on its proteins and no information about its lipid content. Physiological studies using permeabilized cells showed the involvement of a bafilomycin $A_{1}$-sensitive vacuolar $\mathrm{H}^{+}$-ATPase in the process of acidification and of a vanadate-sensitive $\mathrm{Ca}^{2+}$-ATPase in the uptake of $\mathrm{Ca}^{2+}$ (Vercesi et al. 1994, Docampo et al. 1995, Scott et al. 1995, Moreno \& Zhong 1996, Lu et al. 1997, Marchesini et al. 2000). These observations were also confirmed for trypanosomatids and Apicomplexa, using intact cells loaded with fura-2, a fluorescent indicator of $\mathrm{Ca}^{2+}$ (Review in Docampo and Moreno 1999). The use of an immunochemical (immunobloting, immunoprecipitation and immunocytochemistry) approach showed the presence of the following enzymes in the membrane of the acidocalcisomes of trypanosomatids: (a) a vacuo- lar $\mathrm{H}^{+}$-ATPase (Benchimol et al. 1998, Moreno et al. 1998), (b) a $\mathrm{Ca}^{2+}-\mathrm{H}^{+}-$translocating ATPase whose gene was cloned, sequenced and expressed. Antibodies generated against the protein product of the gene (Tca1) labeled the membrane of the acidocalcisome as well as the plasma membrane of $T$. cruzi (Lu et al. 1998); (c) a vacuolar-type protontranslocating pyrophosphatase $\left(V-H^{+}\right.$-PPase $)$was identified and localized in the membrane of the acidocalcisome and in the plasma membrane of trypanosomatids and Apicomplexa, using antibodies recognizing the enzyme found in plants (Scott et al. 1998, Luo et al. 1999, Rodrigues et al. 1999, 2000). The functional properties of this enzyme has been characterized in some detail in studies analyzing the effect of inorganic pyrophosphate, and pyrophosphate analogues, on the acidification of isolated acidocalcisomes (Rodrigues et al. 2000); (d) evidence has been obtained for the presence of a $\mathrm{Na}^{+}-\mathrm{H}^{+}$ exchanger and $\mathrm{C} \mathrm{Ca}^{2+}-\mathrm{H}^{+}$exchanger in the membrane of the acidocalcisome (Vercesi \& Docampo 1996, Vercesi et al. 1997).

What are the functions played by the acidocalcisome? In a recent review, Docampo and Moreno 


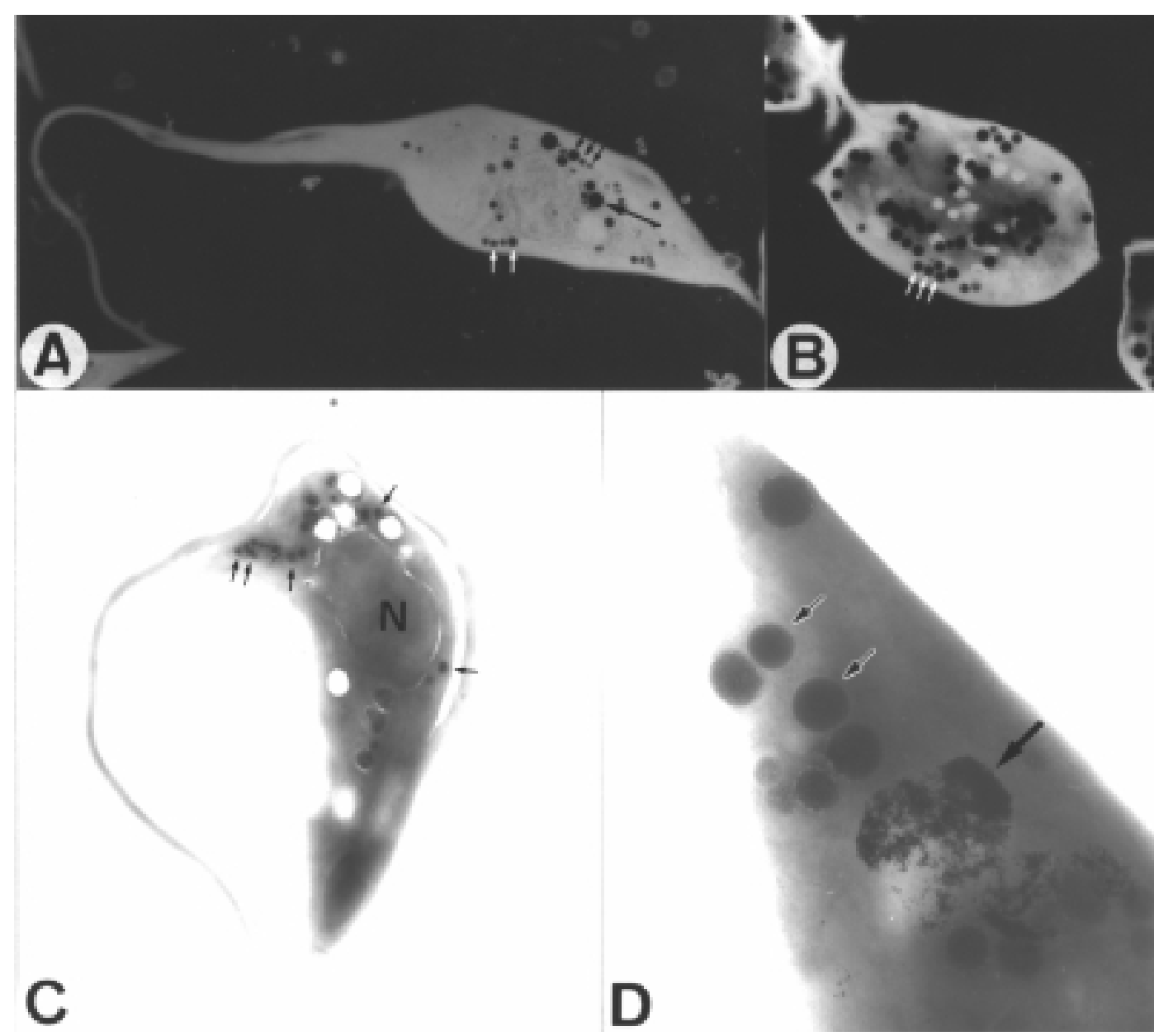

Fig. 2 - (A-C) Whole intact cell adhered to formvar-carbon coated copper grids submitted to air drying without any previous treatment with fixatives or dehydrating agents. (A and B) Electron spectroscopic images (ESI) of a whole epimastigote (A) and a whole amastigote (B) showing the distribution of acidocalcisomes (arrows) throughout the parasite's body. (C) Bright field image of a trypomastigote form showing the preferential localization of the acidocalcisomes at the anterior portion of the parasite. (D) Whole epimastigote submitted to endocytosis of gold-labeled albumin, showing the acidocalcisomes (small arrows) and a reservosome filled with the gold tracer (larger arrow. (A) X 4,800 (B) X 9,000 (C) X 8,000 (D) X 27,400.

(1999) considered four possibilities which are not excludent. Indeed, based on the information available, it is possible that this organelle is involved in several biological processes. (a) The first possibility is a role in the process of $\mathrm{Ca}^{2+}$ storage to be used in certain moments of the parasite's life cycle. For instance, amastigote forms of T. cruzi live in the cytoplasm of the host cell, where the $\mathrm{Ca}^{2+}$ concentration is in the range of $0.1 \mu \mathrm{M}$ in contrast to the trypomastigote form, that lives in an environment where the concentration is around $1 \mathrm{mM}$. Since $\mathrm{Ca}^{2+}$ is involved in several sinalization processes, including cell transformation, cell interaction, etc., the amastigote form of $T$. cruzi developed a special way to accumulate this ion in the acidocalcisome, as it would not be available in the intracel- 
lular environment, where this developmental stage of the parasite lives, thus explaining the presence of a large number of acidocalcisomes in amastigote forms (Lu et al. 1998); (b) A second role would be to act as an energy store organelle, containing a large amount of inorganic PPi. It is expected that further biochemical studies on this area will lead to new information on the bioenergetics of protozoa, opening new perspectives for the development of new parasitic drugs; (c) in view of the presence of a $H^{+}$-ATPase in the membrane of the acidocalcisome, it can also play some role in the regulation of the cytoplasmic $\mathrm{pH}$; (d) the acidocalcisome can also play some role on the osmoregulation control, as another organelle known as acidosome does in Dictyostelium discoideum, which presents an elaborated contractile vacuole system (Nolta et al. 1991, Bush et al. 1994). A similar vacuolar system has been characterized in Leptomonas collosoma (Linder \& Staehelin 1977) and similar structures, with various degrees of development, is found near the flagellar pocket of all trypanosomatids (De Souza, unpublished observations).

\section{THE RESERVOSOME}

The epimastigote stage of the members of the Trypanosoma genus belonging to the Schyzotrypanum sub-genus, such as Trypanosoma cruzi, Trypanosoma vespertilionis e Trypanosoma dionisii, presents one special organelle, recently designated as reservosome (Soares \& De Souza 1988). Each epimastigote form presents several reservosomes, mainly localized in the posterior region of the cell (Figure 3A). Although its morphology can vary according to the growth conditions and the parasite strain (Figure 3A,B), it is a usually spherical organelle, with a mean diameter of 400-600 nm, surrounded by a unit membrane (Soares \& De Souza 1988). The matrix of the reservosome is slightly dense and presents some inclusions. Cytochemical studies have shown that the matrix is mainly made of proteins and the inclusions contain lipids (Soares $e t$ al. 1987). The organelle was designated as reservo- some based on two criteria. First, because all macromolecules ingested by the parasite through an endocytic process, which takes place in the cytostome and the flagellar pocket as will be discussed below, accumulate in the organelle (Figure 3C). Second, because it gradually disappears when epimastigotes are incubated in a poor culture medium, condition that triggers the process of transformation from noninfective epimastigote into infective trypomastigote forms (Soares et al. 1989). The reservosome can be easily identified by fluorescence microscopy as an orange to red stained structure when epimastigotes are incubated in the presence of acridine orange, a dye that accumulates into acidic compartments. The determination of the $\mathrm{pH}$ of the organelle, using the DAMP technique, indicated a value of $\mathrm{pH} 6.0$, thus suggesting that the reservosome corresponds to a pre-lysosomal compartment (Soares et al. 1992). No acid phosphatase activity could be systematically detected in the organelle.

One characteristic feature of the reservosome in T. cruzi is to accumulate a large amount of cruzipain, the major cysteine proteinase found in the cell (Campetella et al. 1990, Meirelles et al. 1990, Murta et al. 1990, Souto-Padrón et al. 1990). Although glicosylated, these proteins do not present mannose-6-phosphate residues. No mannose-6phosphate receptors could be immunocytochemically detected in T. cruzi (Soares et al. 1992). Therefore, another, not yet characterized, intracellular route is used to deliver cruzipain to the endosomal system.

The biogenesis of the reservosome has been studied using exogenous proteins which can be detected due to its intrinsic enzymatic activity (Figure 3D) or due to the fact that they are associated to colloidal gold particles (Figure 3C) (Soares \& De Souza 1991, Figueiredo et al. 1994, Porto Carreiro et al. 2000). These studies have shown that proteins are mainly ingested through the cytostome (Figure 4A), a highly specialized structure found on the surface of the parasite, close to the flagellar pocket, and through the flagellar pocket itself. In all cases, 


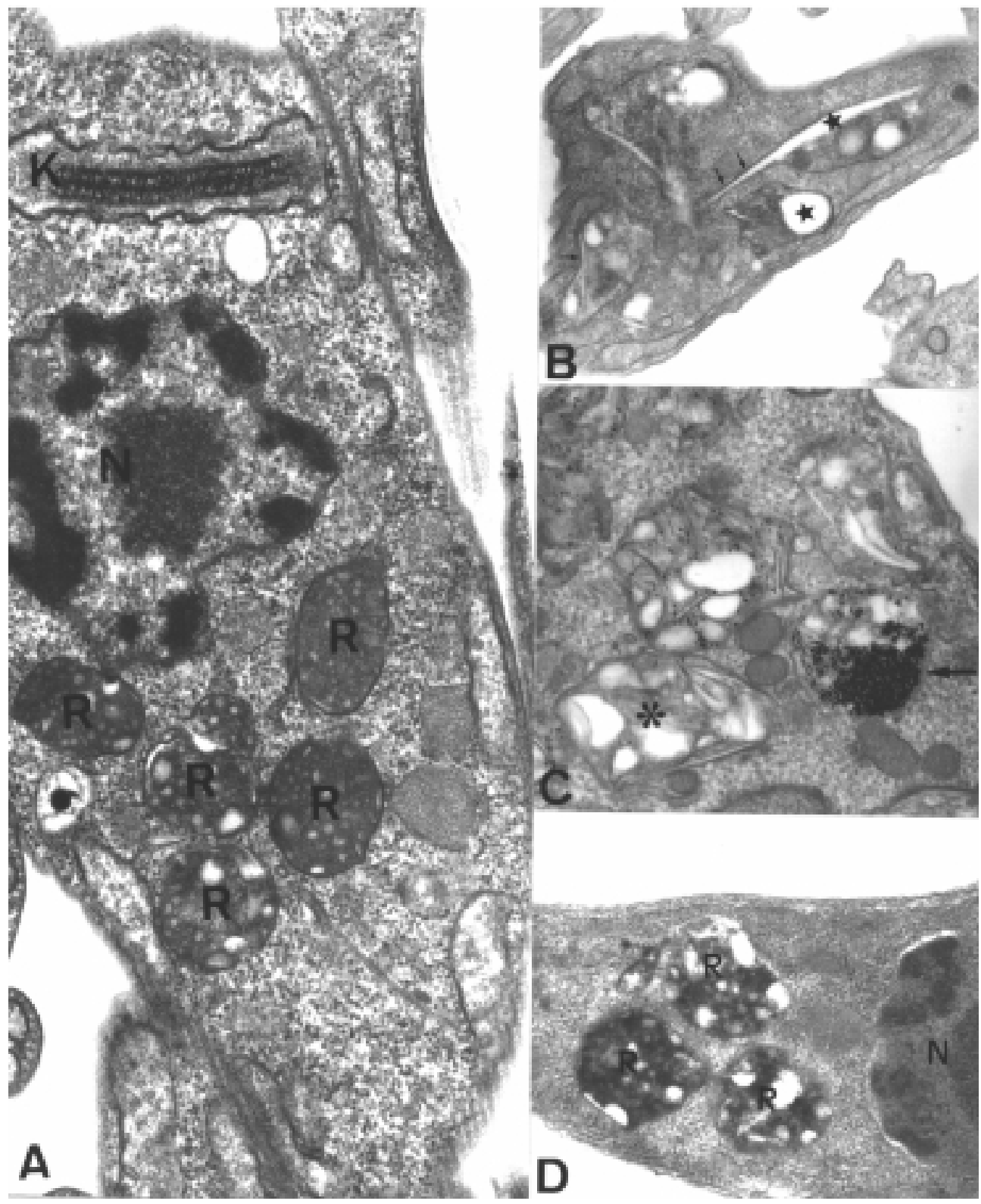

Fig. 3 - Thin sections showing three to five-day old cultured epimastigotes from Y strain (A) and Dm 28 clone (B). In (A), a longitudinal section showing the typical intracellular localization of reservosomes $(\mathrm{R})$, at the posterior portion of the parasite, near the nucleus $(\mathrm{N})$; K, kinetoplast. In (B) reservosomes from Dm28 clone, that under some culture conditions, can depict a very heterogeneous form, containing huge electron-lucent inclusions (stars) that seem to disrupt the organelle (small arrows). (C) Reservosomes (R) from CL Brener epimastigotes that uptaken gold-labeled albumin for 1 hour. In the same parasite, we can find some reservosomes very full of the tracer (arrow), while others contain almost none (asterisk). Protein uptake can also be demonstrated by its enzymatic activity (D) : reservosomes are full of exogenously added horseradish peroxidase, subsequently revealed with diaminobenzidine; N, nucleus. (A) X 28,200 (B) X 20,500 (C) X 34,100 (D) X 30,700. 


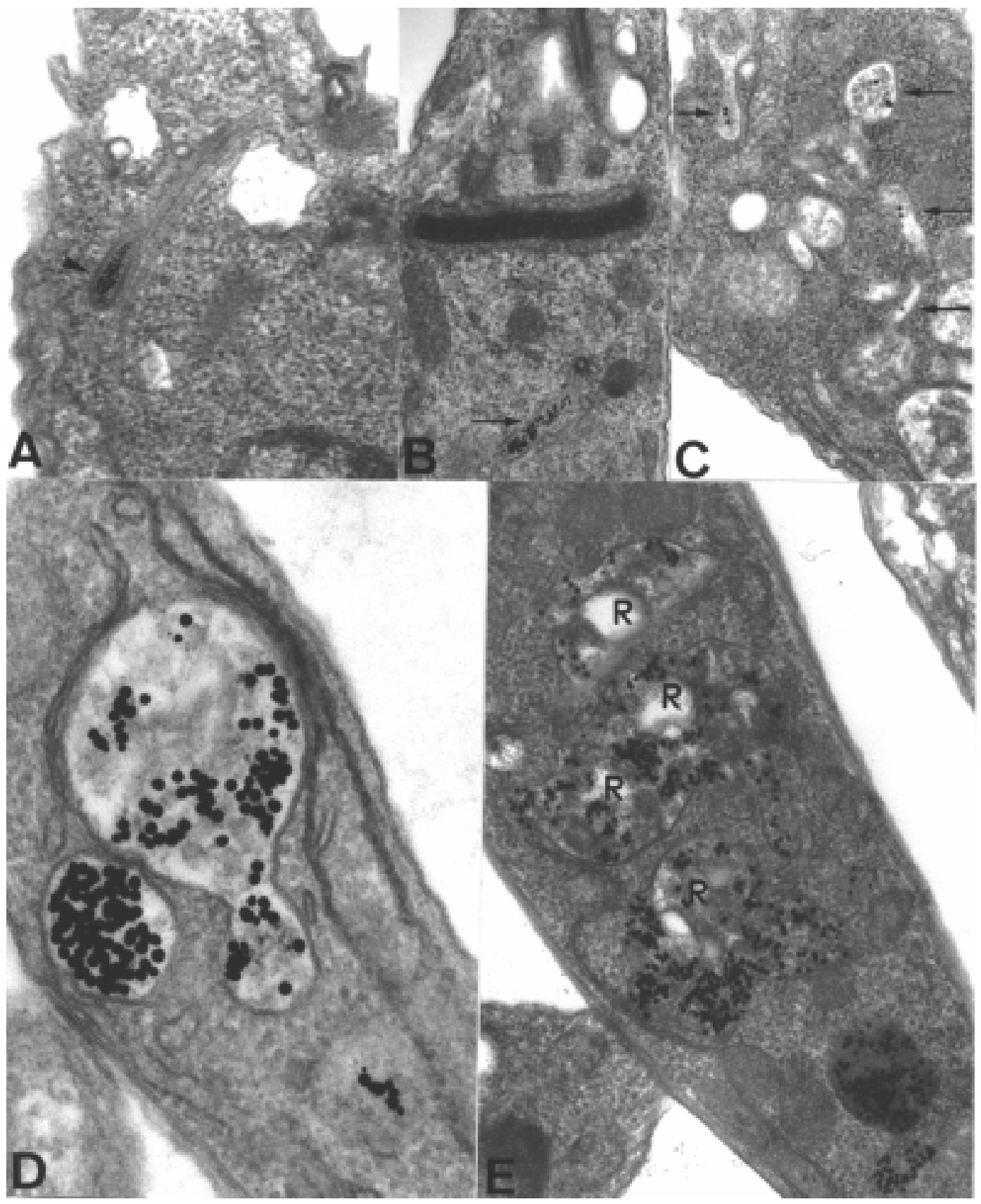

Fig. 4 - Epimastigotes internalize gold-labeled albumin: the tracer enters preferentially by the cytostome (A, arrowhead) and is subsequently found inside vesicles and tubules (arrows in B, 2 minutes of uptake; C, 5 minutes; D, 15 minutes), accumulating in reservosomes (R) after 30 minutes (E). (A) X 34,800 (B) X 31,300 (C) X 25,200 (D) 78,300 (E) X 34,800. 
small cytoplasmic vesicles are formed (Figure 4B,C). These vesicles fuse with each other (Figure 4D), forming an intrincated and branched tubular network distributed from the perinuclear region to the posterior end of the cell, and which may correspond to the early endosomal system of the protozoan (Porto Carreiro et al. 2000). Later on vesicles bud from the tubular system and fuse to form the reservosome, accumulating therein (Figure 4E).

\section{REFERENCES}

ANDERSON WA \& ELLIS RA. 1965. Ultrastructure of Trypanosoma lewisi: flagellum, microtubules and the kinetoplast. J Protozool 12: 483-489.

Benchimol M, De Souza W, Vanderheyden N, Zhong L, Lu H-G, Moreno S \& Docampo R. 1998. Functional expression of a vacuolar-type $\mathrm{H}^{+}$-ATPase in the plasma membrane and intracellular vacuoles of Trypanosoma cruzi. Biochem J 332: 695-702.

BLum JJ. 1989. Changes in orthophosphate, pyrophosphate and long-chain polyphosphate levels in Leishmania major promastigotes incubated with and without glucose. J Protozool 36: 254-257.

Bush J, Nolta K, Rodriguez-Paris J, Kaufmann N, O’Halloran T, Ruscetti T, Temesvari L, Steck T \& Cardelli J. 1994. A rab4-like GTPase in Dictyostelium discoideum in reticular membranes of the contractile vacuole complex and in lysosomes. $J$ Cell Sci 107: 2801-2812.

Campetella O, Martinez J \& Cazzulo JJ. 1990. A major cysteine proteinase is developmentally regulated in Trypanosoma cruzi FEMS Microbiol Lett 67: 145-150.

Carvalho TU \& De Souza W. 1977. Fine structure and X-ray microanalysis of electron dense granules in Herpetomonas samuelpessoai. J Parasitol 63: 11161117.

Carvalho TU, Souto-Padron T \& De Souza W. 1979. Herpetomonas samuelpessoai: electron microscopy and cytochemistry of electron-dense granules. Exp Parasitol 47: 297-304.
Coppens I, Baudhuin P, Opperdoes FR \& Courtoy PJ. 1993. Role of acidic compartments in Trypanosoma brucei, with special reference to low-density lipoprotein processing. Mol Biochem Parasitol 58: 223-232.

Docampo R \& Moreno SNJ. 1999. Acidocalcisome: a novel $\mathrm{Ca}^{2+}$ storage compartment in trypanosomatids and Apicomplexan parasites. Parasitol Today 15: $443-448$.

Docampo R, Scott DA, Vercesi AE \& Moreno SNJ. 1995. Intracellular $\mathrm{Ca}^{2+}$ storage in acidocalcisomes of Trypanosoma cruzi. Biochem J 310: 1005-1012.

Dvorak JA, Engel JC, Leapman RD, Swyt CR \& Pella PA. 1988. Trypanosoma cruzi: elemental composition heterogeneity of cloned stocks. Mol Biochem Parasitol 31: 19-26.

Figueiredo, R C B Q, Steindel M \& Soares M J. 1994. The reservosomes of epimastigote forms of Trypanosoma cruzi: occurrence during in vitro cultivation. Parasitol Res 80: 517-522.

Heywood P, Weinman D \& Lipman M. 1974. Fine structure of Trypanosoma cyclops in non-cellular cultures. J Protozool 21: 232-238.

JanAKIDEVi K, Dewey VC \& Kidder GW. 1965. The nature of the inorganic polyphosphates in a flagellated protozoan. J Biol Chem 240: 1754-1757.

LeFurgey A, Ingram P \& Blum JJ. 1990. Elemental composition of polyphosphate-containing vacuoles and cytoplasm of Leishmania major. Mol Biochem Parasitol 40: 77-86.

Linder JC \& Staehelin, LA. 1977. Plasma membrane specializations in a trypanosomatid flagellate. $\mathrm{J} \mathrm{Ul}$ trastruct Res 60: 246-262.

Lu H-G, Zhong L, Chang KP \& Docampo R. 1997. Intracellular $\mathrm{Ca}^{2+}$ pool content and signaling, and expression of a calcium pump are linked to virulence in Leishmania mexicana amazonensis. J Biol Chem 272: 9464-9473.

Lu H-G, Zhong L, De Souza W, Benchimol M, Moreno SJN \& Docampo R. 1998. $\mathrm{Ca}^{2+}$ content and expression of an acidocalcisomol calcium pump are elevated in intracellular forms of Trypanosoma cruzi. Mol Cell Biol 18: 2309-2323. 
Luo SH, Marchesini N, Moreno SNJ \& Docampo R. 1999. A plant-like vacuolar $H^{+}$-pyrophosphatase in Plasmodium falciparum. FEBS Lett 460: 217-220.

Marchesini N, Luo S, Rodrigues CO, Moreno SNJ \& Docampo R. 2000. Acidocalcisomes and a vacuolar $\mathrm{H}^{+}$-pyrophosphatase in malarial parasites. Biochem J 347: 243-253.

Meirelles MnL, Juliano L, Carmona E, Costa EM, Silva SG, Lima ATVC, Arnholdt AV, Leme VMC, Guimarães ESP, Berro OJ \& SCharfstein J. 1990. Functional and antigenic properties of the major cysteine proteinase (GP 57/51) of Trypanosoma cruzi. Mem Inst Oswaldo Cruz 85: 533-538.

Meldolesi J, Madeddu L \& Pozzan T. 1990. Intracellular $\mathrm{Ca}^{2+}$ storage organelles in non-muscle cells: heterogeneity and functional assignement. Biochim Biophys Acta 1055: 130-140.

Meyer A. 1904. Orientierende Untersuchungen ueber Verbreitung Mhorphologie, und Chemie des Volutins. Bot Zeit 62: 113-152.

Miranda K, Benchimol M, Docampo R \& De Souza W. 2000. The fine structure of acidocalcisomes in Trypanosoma cruzi. Parasitol Res 86: 373-384.

Moreno SNJ \& Zhong L. 1996. Acidocalcisomes in Toxoplasma gondii tachyzoites. Biochem J813: 655659.

Moreno SnJ, Zhong L, De Souza W \& Benchimol M. 1998. Vacuolar-type $H^{+}$-ATPase regulates cytoplasmic $\mathrm{pH}$ in Toxoplasma gondii. Biochem J 330: 853-860.

Murta ACM, Persechini PM, Souto-Padrón T, De Souza W \& Scharfstein J. 1990. Structural and functional identification of GP 57/51 antigen of Trypanosoma cruzi as a cysteine proteinase. Mol Biochem Parasitol 43: 27-38.

Nolta KV, Padh H \& Steck TL. 1991. Acidosomes from Dictyostelium. Initial biochemical characterization. J Biol Chem 266: 18318-18323.

ORMEROD WE. 1958. A comparative study of cytoplasmic inclusions (volutin granules) in different species of trypanosomes. J Gen Microbiol 19: 271-288.

Philosoph H \& Zilberstein D. 1989. Regulation of intracellular calcium in promastigotes of the human protozoan parasite Leishmania donovani. J Biol Chem 264: 10420-10424.

Porto-Carreiro I, Attias M, Miranda K, De Souza W \& CunHa-E-Silva NL. 2000. Trypanosoma cruzi epimastigotes Endocytic pathway: cargo enters the Cytostome and passes through an early endosomal network before reservosome storage. Eur J Cell Biol, in press.

Rodrigues CO, Scott DA \& Docampo R. 1999. Characterization of a vacuolar pyrophosphatase in Trypanosoma brucei and its localization to acidocalcisomes. Mol Cell Biol 19: 7712-7723.

Rodrigues CO, Scott DA, Bailey B, De Souza W, Benchimol M, Urbina J, Oldfield E \& Moreno SNJ. 2000. Vacuolar proton pyrophosphatase activity and pyrophosphate in Toxoplasma gondii as possible chemotherapeutic targets. Biochem J 349: 737-745.

Rooney EK \& Gross JD. 1992. ATP-driven $\mathrm{Ca}^{2+} / \mathrm{H}^{+}$ antiport in acid vesicles from Dictyostelium. Proc Natl Acad Sci USA 89: 8025-8029.

Ruben L, Hutchinson A \& Moehlman J. 1991. Calcium homeostasis in Trypanosoma brucei. Identification of a $\mathrm{pH}$-sensitive non-mitochondrial calcium pool. J Biol Chem 266: 24351-24358.

Scott DA, Moreno SNJ \& Docampo R. 1995. $\mathrm{Ca}^{2+}$ storage in Trypanosoma brucei: the influence of cytoplasmic $\mathrm{pH}$ and importance of vacuolar acidity. Biochem J 310: 789-794.

Scott DA, Docampo R, Dvorak JA, Shi S \& Leapman RD. 1997. In situ compositional analysis of acidocalcisomes in Trypanosoma cruzi. J Biol Chem 272: 28020-28029.

Scott DA, De Souza W, Benchimol M, Zhong L, Lu H-G, Moreno SNJ \& Docampo R. 1998. Presence of a plant-like proton pumping pyrophosphatase in acidocalcisomes of Trypanosoma cruzi. J Biol Chem 273: 22151-22158.

Soares MJ \& De Souza W. 1988. Cytoplasmic organelles of Trypanosomatids: a cytochemical and stereological study. J Submicrosc Cytol Pathol 20: 349-361. 
SoAres MJ \& De Souza W. 1991. Endocytosis of goldlabeled proteins and LDL by Trypanosoma cruzi. Parasitol Res 77: 461-468.

Soares MJ, De Souza M F \& De Souza W. 1987. Ultrastructural Visualization of Lipids in Trypanosomatids. J Protozool 34: 199-203.

Soares MJ, Souto-Padrón T, Bonaldo M C, GoldENBERG S \& De Souza W. 1989. A stereological study of the differentiation process in Trypanosoma cruzi. Parasitol Res 75: 522-527.

Soares MJ, Souto-Padrón T \& De Souza W. 1992. Identification of a large pre-lysosomal compartment in a pathogenic protozoan. J Cell Sci 102: 157-167.

Souto-Padrón T, Campetella O, Cazzulo JJ \& De Souza W. 1990. Cysteine proteinase in Trypanosoma cruzi: immunocytochemical localization and involvement in parasite-host interaction. J Cell Sci 96: $485-490$.

Urbina JA, Moreno B, Vieerkotter S, Oldfield E, Payares G, Sanoja C, Bailey BN, Yan W, Scott DA, Moreno SNJ \& Docampo R. 1999. Trypanosoma cruzi contains major pyrophosphate stores and its growth in vitro is blocked by pyrophosphate analogs. J Biol Chem 274: 33609-33615.
Vercesi AE \& Docampo R. 1996. Sodium-proton exchange stimulates $\mathrm{Ca}^{2+}$ release from acidocalcisomes of Trypanosoma brucei. Biochem J 315: 265-270.

Vercesi AE, Moreno SNJ \& Docampo R. 1994. $\mathrm{Ca}^{2+} / \mathrm{H}^{+}$exchange in acidic vacuoles of Trypanosoma brucei. Biochem J 304: 227-233.

Vercesi AE, Grijalba MT \& Docampo R. 1997. Inhibition of $\mathrm{Ca}^{2+}$ release from Trypanosoma brucei acidocalcisomes by 3,5-dibutyl-4-hydroxytoluene (BHT): role of the $\mathrm{Na}^{+} / \mathrm{H}^{+}$exchanger. Biochem $\mathrm{J}$ 328: $479-482$.

Vickerman K \& TetLey L. 1977. Recent ultrastructural studies on trypanosomes. Ann Soc Belge Med Trop 57: 441-455.

Williamson J \& MCLaren DJ. 1981. Localization of phosphatases in Trypanosoma rhodesiense. J Protozool 28: 460-467. 